\title{
Impact of planned amniotomy on perinatal outcome: a randomized control trial
}

\author{
Shachi Joshi*, Rutul Kapadia, Ajesh Desai
}

Department of Obstetrics and Gynecology, GMERS Medical College, Civil Hospital, Sola, Gujarat, India

Received: 26 April 2017

Accepted: 22 May 2017

\section{*Correspondence:}

Dr. Shachi Joshi,

E-mail: joshishachi89@yahoo.in

Copyright: (C) the author(s), publisher and licensee Medip Academy. This is an open-access article distributed under the terms of the Creative Commons Attribution Non-Commercial License, which permits unrestricted non-commercial use, distribution, and reproduction in any medium, provided the original work is properly cited.

\section{ABSTRACT}

Background: O'Driscoll and Meagher (1968) introduced amniotomy as a component of active management of labour. Several institutions have implemented components of this management scheme with varying results. There is a risk of cord prolapse, variability in fetal heart rate, increased chances of ascending infection which may culminate in chorioamnionitis. As per certain studies, fetal outcome is similar in case of Amniotomy and spontaneous ruptured membranes. As source of great controversy, the active management of labor, as classically defined, is routinely misunderstood and misapplied in many clinical settings. Some previous randomized trials suggest Amniotomy as an effective and safe method for induction and augmentation of labour without altering rate of cesarean section while some disagree. Hence, the study was designed to evaluate the effect of amniotomy on perinatal outcome.

Methods: As per the selection criteria, 250 women with singleton uncomplicated pregnancy with spontaneous onset of labour admitted in labour ward were enrolled in the study. All cases were randomized and allotted to either study group (ARM group) or control group (SRM group) equally according to random number table generated by computer. Women of study group offered amniotomy at $4 \mathrm{~cm}$ dilatation of cervix. Before doing Amniotomy, fetal lie and presentation, engagement of head and fetal heart sounds were conformed. The results were then recorded.

Results: Planned amniotomy is recommended where the clinician suspects fetal compromise as early detection of MSL in planned amniotomy improves the neonatal outcome. Planned amniotomy does not adversely affect the neonatal outcome in terms of low Apgar score at $5 \mathrm{~min}$, neonatal resuscitation and NICU admission. The incidence of neonates born with MSL in planned amniotomy group is better as compared to neonates born with MSL in SRM group.

Conclusions: T Planned amniotomy does not have any adverse effect on the perinatal outcome as compared to SRM group. The incidence of neonates born with MSL in planned amniotomy group is better as compared to neonates born with MSL in SRM group.

Keywords: Amniotomy, Artificial rupture of membrane, Meconium stained liquor, Spontaneous rupture of membrane

\section{INTRODUCTION}

O’Driscoll and Meagher (1968) introduced amniotomy as a component of active management of labour. ${ }^{1}$ This management system was introduced with a goal of "prevention of prolonged labour (dystocia)". His concern behind it was to overcome the maternal morbidity due to labour dystocia which includes difficult deliveries, instrumental deliveries, dehydration, frequent labour analgesia and chorioamnionitis. Recognizing these physical and psychological stress, O'Driscoll developed the principles of active management of labor to achieve 
efficient uterine contractions to effectively shorten the spontaneous labour in primigravida patients. ${ }^{2}$

Several institutions have implemented components of this management scheme with varying results. Applying only certain tenets of the active management technique was account for the differences in the cesarean rate and use of oxytocin experienced by the investigators. As source of great controversy, the active management of labor, as classically defined, is routinely misunderstood and misapplied in many clinical settings. ${ }^{3}$ There is a risk of cord prolapse, variability in fetal heart rate, increased chances of ascending infection which may culminate in chorioamnionitis. As per certain studies, fetal outcome is similar in case of Amniotomy and spontaneous ruptured membranes. As source of great controversy, the active management of labor, as classically defined, is routinely misunderstood and misapplied in many clinical settings. ${ }^{3}$ Some previous randomized trials suggest Amniotomy as an effective and safe method for induction and augmentation of labour without altering rate of cesarean section while some disagree. ${ }^{4-8}$ Hence, the study was designed to evaluate the effect of amniotomy on perinatal outcome. The objective of the study was the safety in terms of rate of Chorioamnionitis and neonatal septicaemia. To study and compare the perinatal outcome in view of APGAR score, requirement of resuscitation, NICU admission, duration of NICU admission and perinatal mortality.

\section{METHODS}

The Randomized control study is carried out in the Department of Obstetrics and Gynecology at GMERS Medical College and Hospital, Sola, Ahmedabad. The study was conducted from April 2014 to March 2016. All nullipara women delivering in the labour room of GMERS Medical College and Hospital during study period. Sampling Method was by comparison of two means and the sample size was 250 .

\section{Selection criteria for pregnant women with spontaneous onset of labour}

Primigravida, Single intra uterine live fetus with cephalic presentation with spontaneous onset of labour between $37^{\text {th }}$ completed weeks till $42^{\text {nd }}$ weeks of gestation and Cervical dilatation $\leq 3 \mathrm{~cm}$ with Intact membranes and assuring non-stress test. As per the selection criteria, 250 women with singleton uncomplicated pregnancy with spontaneous onset of labour admitted in labour ward were enrolled in the study. On admission, patient was given the patient information sheet and written informed consent taken. Detailed history was taken and obstetric examination was carried out. For every patient, non-stress test (cardiotocography) was performed. ${ }^{9}$ Data was recorded in standard proforma.

All cases were randomized and allotted to either study group (ARM group) or control group (SRM group) equally according to random number table generated by computer. During whole labour, all patients were educated about process of labour, all the procedures and management options for labour. Enough time was devoted for each patient and patient handled carefully.

Women of study group offered amniotomy at $4 \mathrm{~cm}$ dilatation of cervix. ${ }^{10}$ Before doing Amniotomy, fetal lie and presentation, engagement of head and fetal heart sounds conformed. Immediately after amniotomy, cord prolapse was ruled out before removing fingers. Fetal heart sounds were rechecked and Cardiotocography performed again to see for cord compression. ${ }^{11}$

Labour monitored by Partograph in both study and control group. Whenever the action line in partograph was reached or arrest of descent was diagnosed or fetal distress occurred actions were taken namely an operative vaginal delivery or cesarean section. After delivery, events of labour and neonatal data were recorded. ${ }^{12,13}$

\section{Outcome measurements}

- Complications of amniotomy (Cord prolapse, chorioamnionitis)

- Neonatal complications (Birth asphyxia, MFAS, jaundice, convulsion) Perinatal mortality. ${ }^{14,15}$

\section{Statistical analysis}

- For quantitative data: “ $Z$ ” test

- For qualitative data: "Chi square" test. ${ }^{16}$

\section{RESULTS}

Table 1: Correlation of NICU admission rate between both groups.

\begin{tabular}{|c|c|c|c|c|}
\hline Variable & $\begin{array}{l}\text { ARM } \\
\text { group } \\
(\%)\end{array}$ & $\begin{array}{l}\text { SRM } \\
\text { group } \\
(\%)\end{array}$ & Total & $\begin{array}{l}P \\
\text { value }\end{array}$ \\
\hline & $\mathrm{n}_{1}=125$ & $\mathrm{n}_{2}=125$ & $\mathrm{~N}=250$ & \multirow[b]{2}{*}{0.099} \\
\hline $\begin{array}{l}\text { NICU } \\
\text { admission }\end{array}$ & $32(25.6)$ & $44(35.2)$ & $76(30.4)$ & \\
\hline
\end{tabular}

Table 1 gives information about NICU admission rate in both groups. In our study, we found overall $30.4 \%$ (76) NICU admission. From ARM group 25.6\% (32) neonates and from SRM group $35.2 \%$ (44) neonates were admitted in NICU with various indications.

The $\mathrm{p}$ value for NICU admission was 0.099 suggesting statistically no significant difference in NICU admission rate between both groups.

We found low Apgar score $(<7)$ in $23.6 \%$ (59) neonates at $1 \mathrm{~min}$ and in $1.6 \%$ (4) of neonates at $5 \mathrm{~min}$. In ARM group and SRM group low Apgar score at 1 min and 5 min was calculated in $23.2 \%$ (29), $24.0 \%$ (30), $0.8 \%$ (1) and $2.4 \%$ (3) neonates respectively. 
Table 2: Correlation of incidence of low (<7) Apgar score at $1 \mathrm{~min}$ and $5 \mathrm{~min}$ between both groups.

\begin{tabular}{|lllll} 
Variable & $\begin{array}{l}\text { ARM } \\
\text { Group } \\
(\%)\end{array}$ & $\begin{array}{l}\text { SRM } \\
\text { Group } \\
(\%)\end{array}$ & $\begin{array}{l}\text { Total } \\
(\%)\end{array}$ & $\begin{array}{l}\text { p } \\
\left(\mathbf{n}_{1}=125\right)\end{array}$ \\
$\begin{array}{lllll}\left(\mathbf{n}_{2}=125\right) \\
\text { 1min }\end{array}$ & $29(23.2)$ & $30(24.0)$ & $59(23.6)$ & 0.88 \\
\hline 5min & $1(0.8)$ & $3(2.4)$ & $4(1.6)$ & $0.61 *$ \\
\hline *Yates' correction applied & & & \\
\hline
\end{tabular}

The $\mathrm{p}$ values for Apgar at $1 \mathrm{~min}$ and $5 \mathrm{~min}$ were 0.88 and 0.61 respectively, suggesting difference in incidence of low Apgar score at $1 \mathrm{~min}$ and 5 min with ARM and SRM group was statistically insignificant.

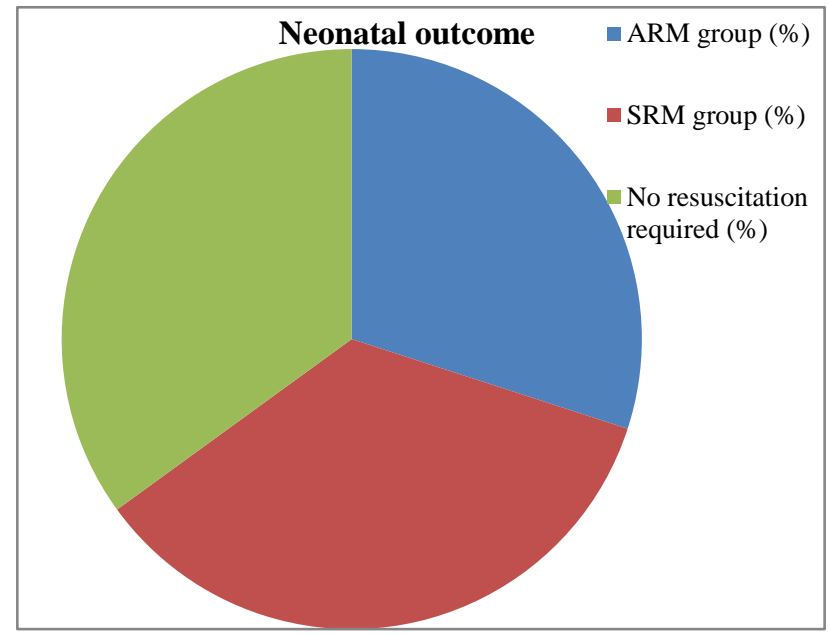

Figure 1: Correlation of need for resuscitation between both groups.

Figure 1 shows correlation of need for different modality of neonatal resuscitation in two groups. During study, neonatal resuscitation was needed for $26.0 \%$ (65) of neonates. In ARM group and SRM group neonatal resuscitation was needed for $24 \%$ (30) and $28 \%$ (35) of neonates respectively. The $\mathrm{p}$ value for need for resuscitation was 0.47 so the difference for requirement of neonatal resuscitation between both the groups was statistically not significant.

Table 3: Correlation of neonatal complications between both groups.

\begin{tabular}{|lllll|} 
& $\begin{array}{l}\text { ARM } \\
\text { Group } \\
(\%)\end{array}$ & $\begin{array}{l}\text { SRM } \\
\text { Group } \\
(\mathrm{n}=125)\end{array}$ & $\begin{array}{l}\text { Total } \\
(\%) \\
(\mathrm{N}=125)\end{array}$ & $\begin{array}{l}\text { p } \\
\text { value }\end{array}$ \\
\hline Jaundice & $23(18.4)$ & $22(17.6)$ & $45(18.0)$ & 0.87 \\
\hline MFAS & $3(2.4)$ & $12(9.6)$ & $15(6.0)$ & $0.033^{*}$ \\
\hline Convulsion & $0(0.0)$ & $3(2.4)$ & $3(1.2)$ & $0.25^{*}$ \\
\hline Septicemia & $5(4.0)$ & $4(3.2)$ & $9(3.6)$ & $0.73^{*}$ \\
\hline Death & 0 & 0 & 0 & \\
\hline
\end{tabular}

*Yates' correction applied
Table 3 shows correlation of neonatal complications between two groups.

During study, we recorded neonatal jaundice within 2 days of birth in $18.0 \%$ (45) of total neonates. In ARM group and SRM group neonatal jaundice developed within 2 days of birth in $18.4 \%$ (23) and $17.6 \%$ (22) of neonates respectively. MFAS was developed in $6.0 \%$ (15) neonates. Out of these $2.4 \%$ (3) and 9.6\% (12) patients were belonging to ARM and SRM group respectively.

Episodes of convulsion were recorded in $1.2 \%$ (3) of total neonates and in SRM group only (2.4\%). No episode of convulsion reported in neonate from ARM group. No neonatal death was recorded out of 250 neonates during study. The $\mathrm{p}$ values for jaundice, MFAS, episodes of convulsion and septicemia were $0.87,0.033,0.25$ and 0.73 respectively. Thus, $\mathrm{p}$ value for incidence of MFAS suggests statistically significantly fewer incidences of MFAS in ARM group as compared to SRM group. For other all three parameters namely jaundice, convulsion and septicemia, the differences in both groups were statistically not significant. No early neonatal death was reported from both the groups during study period.

Table 4: Correlation between neonatal outcome in cases of MSL diagnosed at time of ARM and at time of SRM.

\begin{tabular}{|llll|}
\hline Variable & $\begin{array}{l}\text { ARM Group } \\
\text { n1/N (\%) }\end{array}$ & $\begin{array}{l}\text { SRM } \\
\text { Group } \\
\text { n2/N }(\%)\end{array}$ & $\begin{array}{l}\text { p } \\
\text { value }\end{array}$ \\
\hline Cases of MSL & $6 / 125(4.8)$ & $\begin{array}{l}22 / 125 \\
(17.6)\end{array}$ & \\
\hline $\begin{array}{l}\text { Low APGAR } \\
\text { score (<7 at } \\
\text { 5min) }\end{array}$ & $0 / 6(0.0)$ & $\begin{array}{l}3 / 22 \\
(13.6)\end{array}$ & $0.83 *$ \\
\hline $\begin{array}{l}\text { Incidence of } \\
\text { MFAS }\end{array}$ & $0 / 6(0.0)$ & $\begin{array}{l}10 / 22 \\
(45.5)\end{array}$ & $0.039^{*}$ \\
\hline $\begin{array}{l}\text { Mean duration } \\
\text { of NICU } \\
\text { admission }\end{array}$ & 1.0 days & 3.4 days & $\begin{array}{l}0.041^{*} \\
*\end{array}$ \\
\hline Yates' correction applied; ** "Z” test applied & \\
\hline
\end{tabular}

Table 4 shows correlation of neonatal outcome between cases of MSL diagnosed at time of membrane rupture in ARM group and SRM group. None from ARM group and 6 neonates from SRM group developed MFAS. Mean duration of NICU admission duration in ARM and SRM group was 1.0 day and 3.4 days respectively.

From above data, $\mathrm{p}$ value suggested statistically significantly low incidence of MFAS and less duration of NICU admission in ARM group as compared to SRM group. Thus, early detection of MSL by ARM prevents worsening of perinatal outcome in terms of incidence of MFAS and duration of NICU admission as compared to expectant management. 


\section{DISCUSSION}

Table 5: Comparative analysis of NICU admission rate between different studies.

\begin{tabular}{|llllll|}
\hline $\begin{array}{l}\text { Study } \\
\text { (Year) }\end{array}$ & \multicolumn{2}{l}{ Amniotomy } & \multicolumn{2}{l}{ No } & P \\
& $\mathbf{n} / \mathbf{N}$ & $\mathbf{\%}$ & $\mathbf{n} / \mathbf{N}$ & $\mathbf{\%}$ & \\
\hline Fraser & $40 / 462$ & 8.7 & $37 / 463$ & 8.0 & 0.71 \\
\hline $\begin{array}{l}\text { UK } \\
\text { amniotomy }\end{array}$ & $13 / 193$ & 6.7 & $5 / 180$ & 2.8 & 0.12 \\
\hline Johnson & $13 / 346$ & 3.8 & $12 / 255$ & 4.7 & 0.57 \\
\hline Mikki & $0 / 74$ & 0.0 & $1 / 83$ & 1.2 & 0.95 \\
\hline $\begin{array}{l}\text { Present } \\
\text { study }\end{array}$ & $32 / 125$ & 25.6 & $44 / 125$ & 35.2 & 0.099 \\
\hline
\end{tabular}

NICU admission rate in studies conducted by Fraser (1993), UK amniotomy group (1994), Johnson (1997) and Mikki (2007) were $8.7 \%, 6.7 \%, 3.8 \%$ and $0.0 \%$ in amniotomy group respectively. In no amniotomy group rate of NICU admission was $8.0 \%, 2.8 \%, 4.7 \%$ and $1.2 \%$ respectively.

In present study NICU admission rate was $25.6 \%$ in amniotomy and $35.2 \%$ in no amniotomy group. Above all study including present study does not show statistically significant difference in NICU admission rate between two groups.

\section{CONCLUSION}

Planned amniotomy does not adversely affect the neonatal outcome in terms of low Apgar score at $5 \mathrm{~min}$, neonatal resuscitation and NICU admission. The incidence of neonates born with MSL in planned amniotomy group is better as compared to neonates born with MSL in SRM group.

\section{Recommendations}

Planned amniotomy is recommended where the clinician suspects fetal compromise (abnormal fetal heart rate pattern on NST) as early detection of MSL in planned amniotomy improves the neonatal out-come.

Prophylactic antibiotic is not recommended when planned amniotomy is undertaken as it does not increase the infective neonatal morbidity.

\section{Funding: No funding sources} Conflict of interest: None declared

Ethical approval: The study was approved by the Institutional Ethics Committee

\section{REFERENCES}

1. Boylan PC. Active management of labor: results in Dublin, Houston, London, New Brunswick, Singapore, and Valparaiso. Birth. 1989;16:114-8.

2. O'Driscoll K, Foley M, MacDonald D. Active management of labour as an alternative to cesarean section for dystocia. Obtset gynecol. 1984;63:48590.

3. Pates JA, Satin AJ Active Management of Labor: Obstet Gynecol Clin N Am. 2005;32:221-30.

4. Stewart P, Kennedy JH, Calder AA. Spontaneous labour; when should the membranes be ruptured? $\mathrm{Br}$ J Obstet Gynecol. 1982;89:39-43.

5. Barrett JF, Savage J, Phillips K, Lilford RJ. Randomized trial of Amniotomy in labour versus the intention to leave membranes intact until the second stage. Br J Obstet Gynecol. 1992;99:5-9.

6. Wetrich DW. Effect of Amniotomy upon labour: a controlled study. Obstet Gynecol. 1970;35:800-6.

7. Franks P. A randomized trial of Amniotomy in active labor. J Fam Pract. 1990;30:49-52.

8. Fraser WD, Sauve R, Parboosingh IJ, Fung T, Sokol R, Persaud D. a randomized controlled trial of early Amniotomy. Br J Obstet Gynecol. 1991;98:84-91.

9. Gibb D, Arulkumaran S. Chapter 8. Cardiotocograph interpretation: clinical scenarios. Meconium-stained amniotic fluid. Fetal monitoring in practice. Oxford: Butterworth-Heinemann, 1992:130.

10. Chamberlain G, Zander L, ABC of labour: Induction. BMJ. 1999;318:995-8.

11. Frigoletto F, Lieberman E, Lang J, Cohen A, Barss $\mathrm{V}$, Ringer S. A clinical trial of active management of labour. N Engl J Med. 1995;333:745-50.

12. Sadler LC, Davison T, Mc Cowan LM. Maternal satisfaction with active management of labor: a randomized controlled trial. Birth. 2001;28:225-35.

13. Hayman R. Induction of labour. In: Luseley DM, Baker PN eds. Obstetrics and Gynaecology: An evidence based text for MRCOG. $1^{\text {st }}$ ed. London: Arnold. 2004:327-38.

14. Busowski JD, Parsons MT. Amniotomy to induce labour. Clin Obstetr Gynecol. 1995;38(2):246-58.

15. WHO. Managing complications in pregnancy and childbirth a guide for midwives and doctors. www.who.int/reproductive health/impac/Procedures/Induction (accessed March 2006).

16. Calder AA. Chapter 20. Normal labour. In: Edmonds DK editor(s). Dewhursts textbook of obstetrics and gynaecology for postgraduates. $6^{\text {th }}$ Edition. Blackwell Science; 1999.

Cite this article as: Joshi S, Kapadia R, Desai A. Impact of planned amniotomy on perinatal outcome: a randomized control trial. Int J Reprod Contracept Obstet Gynecol 2017;6:2741-4. 